\title{
Inclined Injection of Supersonic Steam into Subcooled Water: A CFD Analysis
}

\author{
Afrasyab Khan ${ }^{1 . a}$, Khairuddin Sanaullah ${ }^{1 . b}$, M Sobri Takriff ${ }^{2 . c}$ \\ Hushairi Zen ${ }^{3 . d}$, Lim Soh Fong ${ }^{1 . e}$, \\ ${ }^{1}$ Universitiof Malaysia Sarawak (UNIMAS), Faculty of Engineering, Department of Chemical \\ Engineering \& Energy Sustainability, Sarawak, Malaysia \\ ${ }^{2}$ UniversitiKebangsaan Malaysia (UKM), Faculty of Engineering \& Built Environment, Department \\ of Chemical \& Process Engineering, Malaysia \\ ${ }^{3}$ Universitiof Malaysia Sarawak (UNIMAS), Faculty of Engineering, Department of Electronic \\ Engineering, Sarawak, Malaysia \\ aafrasyabunimas@gmail.com, bskhairuddin@feng.unimas.my, 'sobri@eng.ukm.my, , \\ 'zhushair@fenf.unimas.my, ${ }^{\mathrm{e}}$ sflim@feng.unimas.my
}

Keywords: Steam; inclined injection; Pressure; Temperature.

\begin{abstract}
The phenomenon of direct-contact condensation gains attention because of various industrial applications; nuclear reactor emergency core cooling systems,steam driven jet injectors, direct-contact heat exchangers etc..The phenomenon was investigated computationally by injecting an inclined steam jet using a supersonic nozzle submerged in subcooled water. The condensation mechanism is based on two resistance model, which involves consideration of the heat transfer process on both sides of the interface along with use of a variable steam bubble diameter. For computations, ANSYS Fluent based Euler-Euler multiphase model is used. The angle of inclination varies from $5^{\circ}$ to $45^{\circ}$ at constant inlet pressure of 7 bars with water temperature of $30^{\circ} \mathrm{C}$. The maximum penetration length is achieved using a right angled vertical injection.
\end{abstract}

\section{Introduction}

The steam condensation occurs when its vapor comes in to contact with a solid body or liquid interface whose temperature is lower than the saturated temperature of steam. The phenomenon of direct contact condensation attracts much interest from researchers for four decades due to its multifarious engineering applications that includes direct contact heat exchangers; direct contact steam feed water heating system, steam jet driver pumps and nuclear reactor safety system. Steam has several modes of condensation depending upon inlet and outlet pressure and temperature prevailed in the pool of water. When steam is injected in to water different modes of condensation appears that includes chugging, bubbling and jet as reported by Liang et al. [1]. The formation of jet depends on the nozzle exit velocity, as the steam jet condensation takes place into three modes, i.e. subsonic, sonic and supersonic. Research conducted in a decade mainly focussed on investigating the effect of flow parameters on the steam condensation in the subcooled water. This includes the experimental investigation by Xin-Zhuang $\mathrm{Wu}$ et al. [2] who experimentally investigated the condensation heat transfer of sonic steam jet in subcooled water over a wide range of steam mass flux and water temperature. According to his findings four different steam plume shapes were observed and condensation regime map was established, which was based on steam mass flux and water temperature. Correlations for expansion ratio and penetration length were found and axial temperature field measurements were to confirm the existence of compression and expansion waves. Xin-Zhuang Wu et al. [3] investigated the behaviour of the flow patterns of supersonic and sonic steam jet condensation in subcooled water. The effects of steam mass flux, water temperature and pressure ratio on the flow pattern was observed. Their results showed that the expansion and contraction ratios of the steam plume were influenced significantly by pressure ratio. 